\title{
Analysis of neurosurgical reoperations: use of a surgical checklist and reduction of infection-related and preventable complication-related reoperations
}

\author{
Marjut Lepänluoma, MD, ${ }^{1}$ Melissa Rahi, MD, PhD, ${ }^{2}$ Riikka Takala, MD, PhD, ${ }^{3}$ \\ Eliisa Löyttyniemi, MSc, ${ }^{4}$ and Tuija S. Ikonen, MD, PhD ${ }^{5}$ \\ ${ }^{1}$ Faculty of Medicine, University of Turku; '2Division of Clinical Neurosciences, Department of Neurosurgery, and ${ }^{3}$ Perioperative \\ Services, Intensive Care Medicine and Pain Management, Turku University Hospital, Turku; ${ }^{4}$ Department of Biostatistics, \\ University of Turku; and ${ }^{5} \mathrm{Administrative}$ Centre, Hospital District of Southwest Finland, Turku, Finland
}

\begin{abstract}
OBJECT Use of the WHO surgical checklist has been proven to reduce surgical morbidity and mortality, but its effect on surgical complications requiring reoperation has not been previously studied. The aim of this study was to determine whether the use of the WHO surgical checklist would have an impact on the number and causes of neurosurgical complications leading to a reoperation.
\end{abstract}

METHODS The authors retrospectively gathered information on all neurosurgical reoperations using hospital discharge data as well as the operations and procedures registry, and tracked all primary neurosurgical operations $(n=175)$ preceding a complication-related reoperation from 2007 to 2011. There were a total of 5418 neurosurgical operations during the study period. For further analysis of electronic patient records, the primary operations were divided into 2 groups based on the time of the WHO surgical checklist implementation in the authors' unit: 103 operations before and 72 after the introduction of the checklist. Observed adverse events and reoperations were categorized as preventable or unpreventable, and the actual use of the checklist during each operation was recorded.

RESULTS The overall rate of preventable complication-related neurosurgical reoperations decreased from $3.3 \%$ (95\% $\mathrm{Cl} 2.7 \%-4.0 \%)$ to $2.0 \%(95 \% \mathrm{Cl} 1.5 \%-2.6 \%)$ after the checklist implementation. The reoperations were mainly due to wound infections, $46 \%$ before and $39 \%$ after the checklist. All infection-related reoperations proportioned to all neurosurgical operations $(2.5 \%$ before vs $1.6 \%$ after checklist implementation) showed a significant reduction $(p=0.02)$ after the implementation of the checklist. In particular, there was a significant decrease $(p=0.006)$ in the rate of preventable infections associated with reoperations, i.e., $2.2 \%$ before versus $1.2 \%$ after checklist implementation. The overall adherence to checklist use (the "time out" phase) in neurosurgical operations was $78 \%$, and adherence was $70 \%$ in primary operations preceding a complication-related reoperation regarded as preventable.

CONCLUSIONS The implementation of the WHO surgical checklist in neurosurgery was associated with a decrease in complication-related reoperations, especially those due to preventable infection complications, the majority of which were wound infections. The adherence to checklist use in individual operations after the checklist implementation did not appear to have an impact on the results.

http://thejns.org/doi/abs/10.3171/2014.12.JNS141077

KEY WORDS surgical safety checklist; adverse event; reoperation; WHO; infection

$\mathrm{T}$ HE WHO surgical checklist has been studied widely, and its use has been proven to reduce complications and mortality in diverse surroundings and surgical specialties, ${ }^{1,6,19,23,24}$ although in neurosurgery there is only limited research on the topic. ${ }^{11}$ Depending on the type of neurosurgical operation, various studies suggest that adverse event and mortality rates vary between $2 \%-$ 73.5\% and 0\%-2.3\%, respectively. ${ }^{3,4,10,20,27-30}$ Complications may lead to reoperations, with a reported incidence of reoperation rates of $1.5 \%-4.3 \% .^{10,17}$ In our own previous small study, the frequency of reoperation was even higher $(14.7 \%) .{ }^{11}$

ABBREVIATION $\mathrm{Cl}=$ confidence interval.

SUBMITTED May 13, 2014. ACCEPTED December 29, 2014

INCLUDE WHEN CITING Published online February 27, 2015; DOI: 10.3171/2014.12.JNS141077.

DISCLOSURE Dr. Takala has received lecture fees from Abbott, Baxter, and Fresenius Kabi, and has direct stock ownership in Orion Pharma. Dr. Ikonen received funding and financial support for this study from the State Subsidy for University Hospitals, Turku University Hospital, and from a Special Governmental Subsidy for Health Sciences Research in Finland, assigned by the Hospital District of Southwest Finland. Dr. Lepänluoma received a personal research grant from the Finnish Medical Association. 
A reoperation is always a serious and unfortunate complication. To our knowledge, there are no previously published studies of the effect of the WHO surgical safety checklist on the number of complications requiring reoperation. The aim of our study was to determine if the implementation of the WHO surgical checklist had an impact on the occurrence and causes of reoperations due to surgical complications in neurosurgery. For this purpose, we retrospectively analyzed the data of more than 5400 patients who underwent neurosurgical procedures. An additional aim was to detect whether there was a connection between complications and compliance with using the checklist.

\section{Methods \\ Study Criteria}

The study protocol was approved by the Ethical Committee of the Hospital District of Southwest Finland and accepted by the Chief of the Operative Group of Turku University Hospital. The registry database was formed following national legislation in accordance with the ethical standards outlined in the 1964 Declaration of Helsinki.

We searched the discharge data and the hospital registry for operations and procedures at Turku University Hospital from January 2007 to June 2011 that specified neurosurgical primary operations leading to a reoperation due to a neurosurgical complication. Predetermined ICD-10 diagnosis codes (G00, G03, G04, G06, I20-I22, I46-I50, J15, J16, T80, T81, T84, T85, and T88) and surgical procedure codes based on the Nomesco Classification of Surgical Procedures (AAF20, AAF25, AAF90, AAMxx, AAUxx, AAWxx, ABWxx, AWxxx, NAC92, NAG99, NASxx, NAT20, NAWxx, PAUxx, PAWxx, ZSA00, ZSN00, and ZST00) were searched in the registries to identify all neurosurgical complication-related reoperations. The search resulted in 291 matches from 249 complication-related reoperations (Fig. 1). Electronic patient records for all identified patients were examined, and reoperations that were not associated with a neurosurgical complication or preceding neurosurgery were excluded. In addition, 2 reoperations were excluded because the preceding neurosurgical operation took place more than 10 years previously. These criteria led to the exclusion of 54 reoperations. Of the remaining 195 reoperations, 20 were excluded because the preceding neurosurgical procedure was performed before January 2007. This resulted in 175 reoperations that defined the included complication-related episodes and primary operations; a complication-related episode was considered to begin from the preceding neurosurgical procedure (later referred to as the primary operation), which led to the complication-related reoperation.

The study period of January 2007 to June 2011 was divided into 2 periods based on the date of the primary operation and the implementation of the WHO surgical checklist. The period from January 2007 to April 2009 was defined as the period before the checklist and May 2009 to June 2011 as the period after the checklist. There were 103 episodes before and 72 after the checklist imple- mentation (Fig. 1). These groups consisted of 100 patients before and 70 patients after the checklist. Two patients in both groups had 2 separate complication episodes. Another 2 patients were included in both groups: 1 patient had 2 separate complication episodes before and 1 after the checklist, and another patient had 1 episode before and 1 after the checklist. Thus, there were a total of 166 patients in the data set. However, each complication episode was analyzed separately, and the total number of studied episodes was 175 .

\section{Outcome Variables}

The electronic patient records were manually checked for predetermined adverse events by an independent reviewer not involved in the treatment of neurosurgical patients (M.L.). Considered to be adverse events were infections, bleeding, CSF leakage, shunt complications, errors, and delays in diagnosis and/or treatment. The diagnosis of the primary operation and the time span from the primary operation to the complication-related reoperation were also recorded.

The complications involved in each complication episode leading to reoperation were retrospectively analyzed and categorized as theoretically preventable and unpreventable events, based on a consensus of 2 experienced specialists in neurosurgery (Dr. Rahi and Dr. Kotkansalo). An infection was considered preventable if the contamination or the clinical factors enabling the infection could have been prevented by proper sterile precautions or antibiotic prophylaxis. Other adverse events such as bleeding, CSF leakage, error, and delay were considered preventable when due to suboptimal human action. If the time period between the primary operation and the onset of a complication leading to a reoperation was longer than 4 years, infections and shunt-related complications were considered unpreventable. Infections in patients prone to infections or complications due to contributory factors (such as the arm of the patient's spectacles) leading to skin erosion and exposure of the shunt system were considered unpreventable. All cases were individually analyzed.

The total number of neurosurgical operations in our hospital during the study period was 2665 before (January 2007-April 2009) and 2753 after (May 2009-June 2011) the checklist implementation. The WHO surgical checklist was introduced in our hospital in May 2009. From the beginning of October 2009, the information on the use of the checklist was available in real time via electronic operating room records. The performing of the "sign in," "time out," and "sign out" phases of the checklist are entered separately into the software after using the checklist. We scrutinized these data from the studied primary operations performed after the checklist introduction.

\section{Statistical Analysis}

Data are described as frequencies and proportions. For proportions, 95\% confidence intervals (CIs) were calculated. Even though the data included some patients with 2 separate adverse events, all adverse event episodes were considered independent observations. Therefore, the Fisher's exact test was performed on all association analyses, 


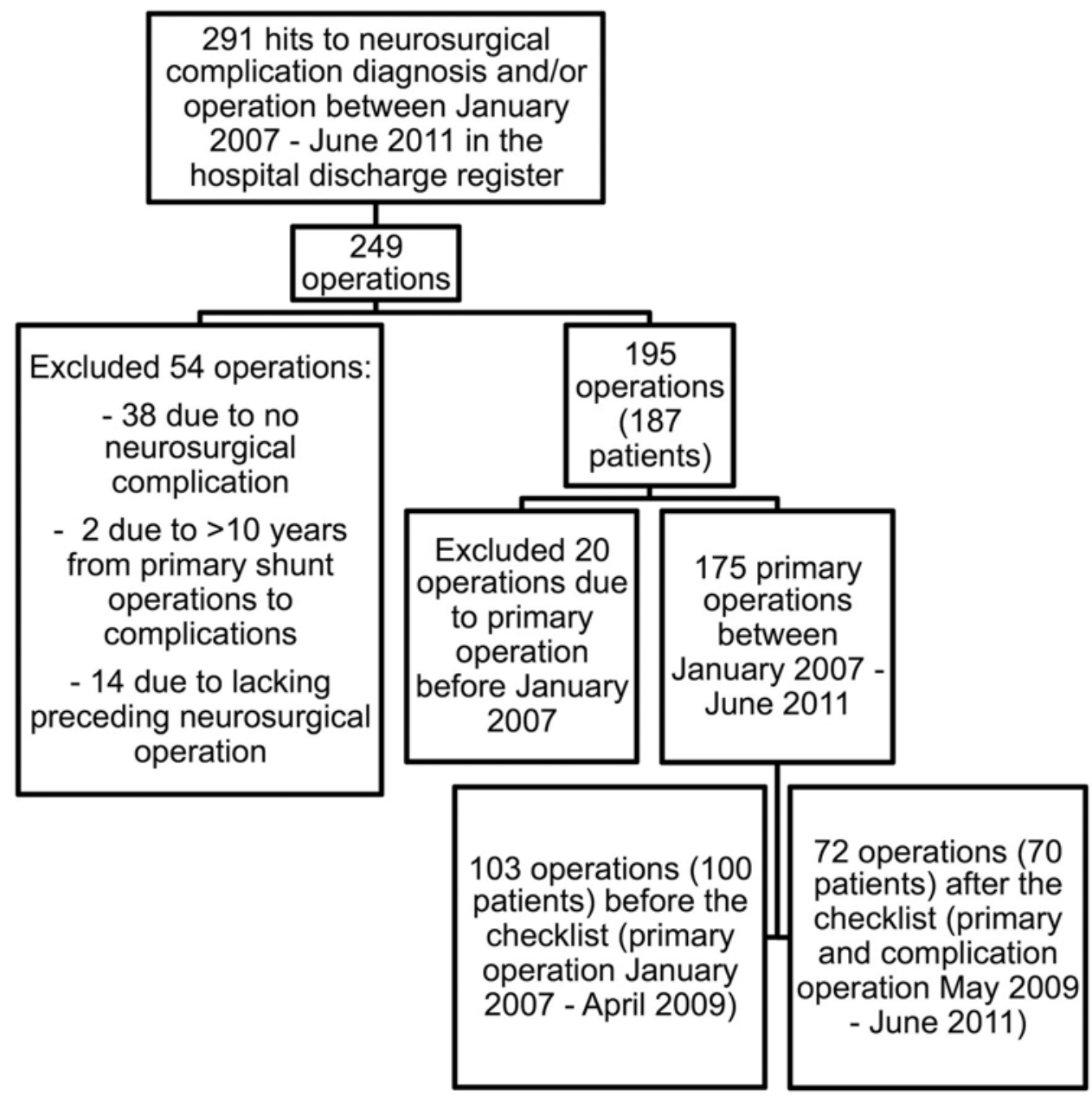

FIG. 1. Flow chart showing exclusion and inclusion of the studied neurosurgical complication-related reoperations for the comparison analysis.

in which proportions before and after checklist implementation were compared with primary operation, diagnosis, complications, and preventable adverse events. Baseline characteristics (sex, age at the time of primary operation, age at the time of complication, and time between primary operation and complication-related reoperation) were analyzed using the Fisher's exact test or Wilcoxon rank-sum test; $\mathrm{p}$ values $<0.05$ were considered statistically significant (2-tailed). The statistical analyses were generated using SAS software (version 9.3 for Windows, SAS Institute).

\section{Results}

The demographics and classified primary operations are presented in Tables 1 and 2, respectively. There were no significant differences between the groups.

The primary operations leading to complication-related reoperations represented $3.9 \%(n=103)$ and $2.6 \%(n=$ 72) of 2665 and 2753 neurosurgical operations before and after checklist implementation, respectively. Of the studied complications, 85\% $(\mathrm{n}=88)$ and $75 \%(\mathrm{n}=54)$ were categorized as preventable before and after checklist im- plementation, respectively $(p=0.12)$. When calculated according to the proportion of the total number of neurosurgical operations during the study period (proportioned), the preventable complications leading to reoperation were significantly lower after the checklist implementation, i.e., $3.3 \%$ (95\% CI $2.7 \%-4.0 \%$ ) before versus $2.0 \%$ (95\% CI $1.5 \%-2.6 \%)$ after implementation.

Classified diagnoses of the complication-related reoperations are presented in Table 3. Most frequently the reoperations were caused by wound infections. There was no statistically significant difference between the groups in any individual diagnosis. However, the rate of wound infections as a cause for reoperation was significantly higher before $(n=47)$ than after $(n=28)$ use of the checklist, representing $1.8 \%$ and $1.0 \%$ of the total number of neurosurgical operations, respectively $(\mathrm{p}=0.02)$. Also the proportion of preventable wound infection diagnoses decreased significantly from $1.7 \%(\mathrm{n}=44)$ to $0.8 \%(\mathrm{n}=23 ; \mathrm{p}=0.0067)$ after the implementation of the checklist.

The reoperations were categorized into preventable (n $=142)$ and unpreventable $(\mathrm{n}=33)$ according to the preventability of the complication leading to the reoperation. 
TABLE 1. Demographics of the patients in the studied primary operations before and after checklist implementation

\begin{tabular}{lcccc}
\hline \multicolumn{1}{c}{ Variable } & Before Checklist & After Checklist & p Value & Test \\
\hline No. of operations & 103 & 72 & & \\
\hline Males/females (\%) & $53(51.5) / 50(48.5)$ & $31(43.1) / 41(56.9)$ & 0.29 & Fisher's exact \\
\hline Mean age at primary operation \pm SD (yrs) & $58.0 \pm 17.0$ & $55.9 \pm 16.4$ & 0.32 & Wilcoxon rank-sum \\
\hline Mean age at complication-related reoperation \pm SD (yrs) & $58.2 \pm 16.9$ & $56.0 \pm 16.4$ & 0.30 & Wilcoxon rank-sum \\
\hline $\begin{array}{l}\text { Mean time between primary operation \& complication-related reop- } \\
\text { eration } \pm \text { SD (days) }\end{array}$ & $100.4 \pm 214.6$ & $34.3 \pm 55.0$ & 0.13 & Wilcoxon rank-sum \\
\hline
\end{tabular}

When examining the distribution of clinical diagnoses (Table 3) there was a significant difference in preventability $(p=0.01)$. The majority of the operations with a wound infection diagnosis were categorized as preventable (67 vs 8 , respectively) and they represented a higher proportion of preventable (47\%) versus unpreventable complications (24\%). On the other hand, complications of spinal or other implants (11 vs 12 operations, respectively) were relatively more frequently unpreventable (36\%) than preventable $(8 \%)$. These results support the internal validity of the assessment of individual patient charts concerning preventability.

The rate of infection-related reoperations decreased significantly after the checklist implementation $(2.5 \%$ before vs $1.6 \%$ after implementation, $p=0.02$; Table 4 ). An even stronger association was found when comparing preventable infection complications leading to neurosurgical reoperations $(2.2 \%$ before vs $1.2 \%$ after, $p=0.006)$. Other adverse events (bleeding, CSF leakage, shunt complications, errors, and delays in diagnosis and/or treatment) did not indicate statistically significant differences before and after the introduction of the checklist, but the number of events was small (Table 4). There were no significant differences in the occurrence of different complications when using the checklist (Table 5).

According to the operating room records (October 2009 to June 2011), the average adherence to performing the time out phase, in which at least the time out phase was performed, was $78 \%$ for all neurosurgical operations after the checklist implementation. At least 1 of the 3 phases of the checklist was used in $68 \%(n=49)$ of the studied primary operations since the checklist introduction in May 2009 ( $\mathrm{n}=72$ ); All phases (sign in, time out, and sign out) were performed in $73 \%(\mathrm{n}=36)$ of these operations, and in an additional $24 \%(n=12)$ of the operations, at least the time out phase was performed, resulting in $67 \%$ compliance with performing the time out phase $(n=48)$. In the primary operations leading to a preventable complication $(\mathrm{n}=54)$, any phase of the checklist was used in $70 \%$ of the operations $(n=38)$; all phases were performed in $76 \%$ of the operations $(n=29)$, and at least the time out phase was performed in an additional 9 operations; thus the overall compliance with performing time out was $70 \%(n=38)$ in primary operations preceding a preventable complication.

TABLE 2. Classified primary operations of the studied neurosurgical complication episodes before and after checklist implementation

\begin{tabular}{|c|c|c|}
\hline Primary Operations* & Before Checklist (\%) & After Checklist (\%) \\
\hline Extirpation or resection of intracranial tumor & $19(18.5)$ & $18(25.0)$ \\
\hline Ligation of intracranial aneurysm & $4(3.9)$ & $1(1.4)$ \\
\hline Trepanation of chronic subdural hematoma & $4(3.9)$ & $3(4.2)$ \\
\hline Ventriculoperitoneal/ventriculoatrial CSF shunts, endoscopic procedures & $25(24.3)$ & $13(18.1)$ \\
\hline Cranioplasty & $3(2.9)$ & $8(11.1)$ \\
\hline Transsphenoidal procedures & $4(3.9)$ & $0(0.0)$ \\
\hline Stereotactic procedures & $0(0.0)$ & $1(1.4)$ \\
\hline Thoracic and/or lumbar decompression \& fusion & $11(10.7)$ & $5(6.9)$ \\
\hline Cervical decompression \& anterior/posterior fusion & $7(6.8)$ & $6(8.3)$ \\
\hline Lumbar laminectomy or microdiscectomy & $13(12.6)$ & $10(13.9)$ \\
\hline Cervical laminectomy or foraminotomy & $5(4.9)$ & $1(1.4)$ \\
\hline Operations for tumors of the spinal cord \& nerve roots & $6(5.8)$ & $2(2.8)$ \\
\hline Angiographic procedure & $1(1.0)$ & $1(1.4)$ \\
\hline Decompression of cranial nerve & $0(0.0)$ & $1(1.4)$ \\
\hline $\begin{array}{l}\text { Other (implantation of spinal injection device, iatrogenic injury to ventriculoperi- } \\
\text { toneal shunt during abdominal surgery) }\end{array}$ & $1(1.0)$ & $2(2.8)$ \\
\hline
\end{tabular}

* No significant difference in a comparison of the distribution of primary operations before versus after checklist implementation $(p=0.26$,

Fisher's exact test). 
TABLE 3. Comparisons of complication-related reoperations after primary operations before and after checklist implementation for all reoperations, and reoperations caused by preventable and unpreventable complications*

\begin{tabular}{|c|c|c|c|c|c|c|}
\hline \multirow[b]{2}{*}{ Diagnosis } & \multicolumn{2}{|c|}{$\begin{array}{c}\text { All Complication-Related } \\
\text { Reoperations }\end{array}$} & \multicolumn{2}{|c|}{$\begin{array}{c}\text { Reoperations Caused by } \\
\text { Preventable Complications }\end{array}$} & \multicolumn{2}{|c|}{$\begin{array}{c}\text { Reoperations Caused by } \\
\text { Unpreventable Complications }\end{array}$} \\
\hline & $\begin{array}{l}\text { Before Checklist } \\
\quad(n=103)\end{array}$ & $\begin{array}{l}\text { After Checklist } \\
\quad(n=72)\end{array}$ & $\begin{array}{l}\text { Before Checklist } \\
\quad(n=88)\end{array}$ & $\begin{array}{l}\text { After Checklist } \\
\quad(n=54)\end{array}$ & $\begin{array}{l}\text { Before Checklist } \\
\quad(n=15)\end{array}$ & $\begin{array}{l}\text { After Checklist } \\
\quad(n=18)\end{array}$ \\
\hline Meningitis & $2(1.9)$ & $0(0.0)$ & $2(2.3)$ & $0(0.0)$ & $0(0.0)$ & $0(0.0)$ \\
\hline Empyema/abscess of CNS & $3(2.9)$ & $3(4.2)$ & $2(2.3)$ & $3(5.6)$ & $1(6.7)$ & $0(0.0)$ \\
\hline $\begin{array}{l}\text { Hemorrhage or hematoma compli- } \\
\text { cating a procedure }\end{array}$ & $14(13.6)$ & $18(25.0)$ & $12(13.6)$ & $13(24.1)$ & $2(13.3)$ & $5(27.8)$ \\
\hline Disruption of wound & $11(10.7)$ & $9(12.5)$ & $11(12.5)$ & $6(11.1)$ & $0(0.0)$ & $3(16.7)$ \\
\hline Wound infection (excl. septicemia) & $47(45.6)$ & $28(38.9) \dagger$ & $44(50.0)$ & $23(42.6) \dagger$ & $3(20.0)$ & $5(27.8)$ \\
\hline $\begin{array}{l}\text { Foreign body or substance left } \\
\text { following procedure }\end{array}$ & $1(1.0)$ & $1(1.4)$ & $1(1.1)$ & $1(1.9)$ & $0(0.0)$ & $0(0.0)$ \\
\hline $\begin{array}{l}\text { Other/unspecified postoperative } \\
\text { complication }\end{array}$ & $7(6.8)$ & $3(4.2)$ & $6(6.8)$ & $3(5.6)$ & $1(6.7)$ & $0(0.0)$ \\
\hline $\begin{array}{l}\text { Complications of spinal implants or } \\
\text { other implants (excl. septicemia) }\end{array}$ & $15(14.6)$ & $8(11.1)$ & $7(8.0)$ & $4(7.4)$ & $8(53.3)$ & $4(22.2)$ \\
\hline $\begin{array}{l}\text { Other complication of surgical \& } \\
\text { medical care }\end{array}$ & $3(2.9)$ & $2(2.8)$ & $3(3.4)$ & $1(1.9)$ & $0(0.0)$ & $1(5.6)$ \\
\hline $\begin{array}{l}\text { p values between groups (Fisher's } \\
\text { exact test) }\end{array}$ & \multicolumn{2}{|c|}{0.65} & \multicolumn{2}{|c|}{0.77} & \multicolumn{2}{|c|}{0.15} \\
\hline
\end{tabular}

excl. = excluding.

* All data given as value (\%).

$\dagger$ A statistically significant difference between the groups before and after the checklist proportioned to the total number of neurosurgical operations during the study period.

\section{Discussion}

To our knowledge this is the first study in which the impact of the WHO surgical safety checklist on the rate and causes of complication-related reoperations has been examined. Our main finding was that the implementation of the surgical checklist for routine use by the neurosurgical operating room teams was associated with a decrease in complication-related neurosurgical reoperations, especially those due to preventable infection-related complications, of which the majority were wound infections.

Previous studies have reported that the use of the checklist reduces the overall rate of adverse events, even mortality, and has a positive impact on communication

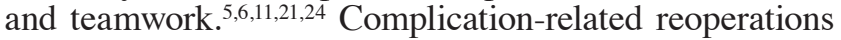
only represent a small part of postoperative complications and can be viewed as serious adverse events leading to significant morbidity and even increased risk of death. We wanted to focus on this specific patient group to analyze the impact of checklist usage on the severe end of the range of adverse events.

We found that the proportion of complication-related reoperations decreased significantly after checklist implementation. All infections leading to reoperations, including wound infections, and especially the infections categorized as preventable, decreased significantly after the implementation of the checklist. During the primary operation preceding a complication-related reoperation, the compliance rate in performing the time out phase of the checklist was on the same level as in all neurosurgical operations. Unexpectedly, the lack of adherence to using the checklist in individual operations did not appear to correlate with the occurrence of preventable adverse events, but this result may be biased due to the delay of 5 months between the implementation and the electronic recording of the use of the checklist. Thus, the real use of the checklist may have been higher than depicted by the records in the operating room electronic charts. The checklist use was optional in emergency operations during the first 5 months, which may have reduced the checklist use compliance to some extent, but did not affect the recorded rate of checklist use.

According to previous studies of unselected neurosurgical operations, surgical-site infection occurs in 1.1\%-4.7\% of the operations..$^{1,14,16}$ In our study, wound infections presented at a rate of $1.0 \%-1.8 \%$, obtained from the surgical diagnoses associated with complication-related reoperations. The effect of perioperative antibiotic prophylaxis on surgical-site infections is controversial, ${ }^{2,7-9,12,14,22}$ but the checklist could have had a positive effect on the reduction of infections by enhancing attention to and compliance with the proper timing of prophylaxis. In our institution there is a fixed protocol for antibiotic prophylaxis in neurosurgery. In the present study we did not have the benefit of determining the timing of antibiotic administration from the electronic patient records, and this could be a focus of further studies. In our previous studies on implementation of this checklist in neurosurgical operations we discovered a systematic error in the timing of antibiotic prophylaxis. ${ }^{11,21}$ Interestingly, the infection rate declined during the implementation of the checklist, even 


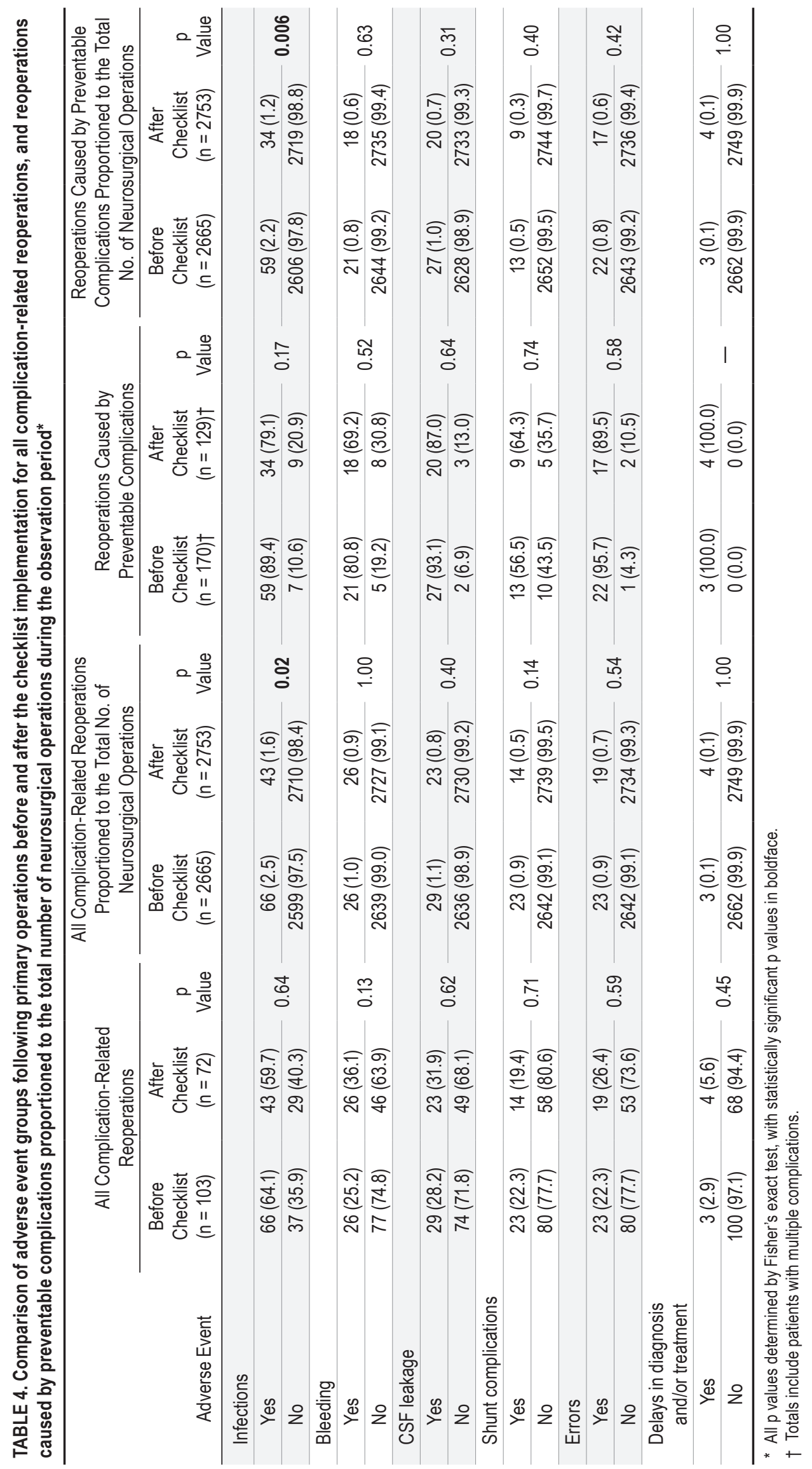


TABLE 5. Use of the WHO surgical checklist in the primary operation compared with each of the categorized adverse events after checklist implementation

\begin{tabular}{|c|c|c|c|}
\hline \multirow[b]{2}{*}{ Adverse Event } & \multicolumn{2}{|c|}{$\begin{array}{c}\text { Use of the Checklist in } \\
\text { Primary Operations After } \\
\text { Implementation }\end{array}$} & \multirow[b]{2}{*}{$\mathrm{p}$ Value } \\
\hline & Yes $(n=49)$ & No $(n=23)$ & \\
\hline \multicolumn{4}{|l|}{ Infection } \\
\hline Yes $(n=43)$ & $30(69.8)$ & $13(30.2)$ & \multirow{2}{*}{0.80} \\
\hline No $(n=29)$ & $19(65.5)$ & $10(34.5)$ & \\
\hline \multicolumn{4}{|l|}{ Bleeding } \\
\hline Yes $(n=26)$ & $14(53.9)$ & $12(46.1)$ & \multirow{2}{*}{0.068} \\
\hline No $(n=46)$ & $35(76.1)$ & $11(23.9)$ & \\
\hline \multicolumn{4}{|l|}{ CSF leakage } \\
\hline Yes $(n=23)$ & $18(78.3)$ & $5(21.7)$ & \multirow{2}{*}{0.28} \\
\hline No $(n=49)$ & $31(63.3)$ & $18(36.7)$ & \\
\hline \multicolumn{4}{|l|}{ Shunt complications } \\
\hline Yes $(n=14)$ & $10(71.4)$ & $4(28.6)$ & \multirow{2}{*}{1.00} \\
\hline No $(n=58)$ & $39(67.2)$ & $19(32.8)$ & \\
\hline \multicolumn{4}{|l|}{ Errors } \\
\hline Yes $(n=19)$ & $10(52.6)$ & $9(47.4)$ & \multirow{2}{*}{0.15} \\
\hline No $(n=53)$ & $39(73.6)$ & $14(26.4)$ & \\
\hline \multicolumn{4}{|c|}{$\begin{array}{l}\text { Delays in diagnosis and/or } \\
\text { treatment }\end{array}$} \\
\hline Yes $(n=4)$ & $2(50.0)$ & $2(50.0)$ & \multirow{2}{*}{0.59} \\
\hline No $(n=68)$ & 47 (69.1) & $21(30.9)$ & \\
\hline
\end{tabular}

* Fisher's exact test.

though the timing error was noticed and corrected first in late 2009. Other checklist-related explanations might be better awareness of patient-related risks, readiness to compensate bleeding, sterile instrument check, and more accurate postoperative prescriptions of antibiotics. During the study period there were no significant changes made in the physical environment, treatment protocols, surgical materials, or dressings that could explain the reduction of infections.

Surgical infection is always a setback. In neurosurgery a simple wound infection may lead to multiple reoperations and long antibiotic treatments, and hence cause greater costs than infections in other surgical specialties..$^{15,25}$ The use of a surgical checklist is simple and inexpensive, and could indirectly save money, ${ }^{18}$ redundant work, and suffering of patients. There is a need for surgical checklists in all types of surgery ${ }^{13}$ but especially in neurosurgery. ${ }^{26}$

There are some limitations to our study. The number of studied complication episodes was rather small, yet the total number of neurosurgical operations during the study period was substantial. The small number of cases in many diagnosis groups might limit the power of the study to demonstrate a statistically significant difference. When proportioned to the volume and the standard of neurosurgical care, even the small enhancements are clinically significant.

The reliability of the hospital discharge register as the source of the primary data may be questioned, but the information for our analysis came directly from the electronic medical records instead of having been separately recorded in the discharge register. In this study we concentrated on complications leading to a reoperation. It is very unlikely that a reoperation performed in the operating room would not be recorded in the electronic operations and procedures registry and/or patient records. To avoid a bias due to missing or incorrect codes we used a wide search, without relying only on complication codes, and obtaining other complication-related diagnosis and procedure codes as well. It is theoretically possible that the defined search terms may have missed occasional cases, but the occurrence of this kind of error would have affected both patient groups.

The average use rate of the checklist in all neurosurgical operations during the study period is not directly comparable to our results of the checklist use rate. There was a gap between the introduction of the checklist in May 2009 and the beginning of the recording of checklist use in the electronic operating room records from the beginning of October 2009. Regardless of this gap, we collected the study data with an intent-to-treat principle from the beginning of May 2009, and operations without a record of checklist use were reported as "no use" cases, although the checklist most likely was used to an unknown extent in these operations.

\section{Conclusions}

Our study indicates that the occurrence of preventable adverse events as the cause of complication-related reoperations among neurosurgical patients was significantly lower after implementation of the WHO surgical safety checklist. In particular, the proportion of both all and preventable wound-infection diagnoses, and the proportion of all and preventable infections leading to a reoperation, decreased significantly after checklist implementation.

\section{Acknowledgments}

We thank Anna Kotkansalo, MD, for her contribution to the categorization and evaluation analysis of the data, and Eva Kiura, BA (diploma in translation), for reading and commenting on the manuscript.

\section{References}

1. Bergs J, Hellings J, Cleemput I, Zurel Ö, De Troyer V, Van Hiel M, et al: Systematic review and meta-analysis of the effect of the World Health Organization surgical safety checklist on postoperative complications. Br J Surg 101:150-158, 2014

2. Haines SJ, Goodman ML: Antibiotic prophylaxis of postoperative neurosurgical wound infection. J Neurosurg 56:103105,1982

3. Halvorsen CM, Lied B, Harr ME, Rønning P, Sundseth J, Kolstad F, et al: Surgical mortality and complications leading to reoperation in 318 consecutive posterior decompressions for cervical spondylotic myelopathy. Acta Neurol Scand 123:358-365, 2011

4. Hammers R, Anzalone S, Sinacore J, Origitano TC: Neurosurgical mortality rates: what variables affect mortality within a single institution and within a national database? J Neurosurg 112:257-264, 2010

5. Haynes AB, Weiser TG, Berry WR, Lipsitz SR, Breizat AH, 
Dellinger EP, et al: Changes in safety attitude and relationship to decreased postoperative morbidity and mortality following implementation of a checklist-based surgical safety intervention. BMJ Qual Saf 20:102-107, 2011

6. Haynes AB, Weiser TG, Berry WR, Lipsitz SR, Breizat AH, Dellinger EP, et al: A surgical safety checklist to reduce morbidity and mortality in a global population. N Engl J Med 360:491-499, 2009

7. Holloway KL, Smith KW, Wilberger JE Jr, Jemsek JG, Giguere GC, Collins JJ: Antibiotic prophylaxis during clean neurosurgery: a large, multicenter study using cefuroxime. Clin Ther 18:84-94, 1996

8. Korinek AM: Risk factors for neurosurgical site infections after craniotomy: a prospective multicenter study of 2944 patients. The French Study Group of Neurosurgical Infections, the SEHP, and the C-CLIN Paris-Nord. Neurosurgery 41:1073-1081, 1997

9. Korinek AM, Golmard JL, Elcheick A, Bismuth R, van Effenterre R, Coriat P, et al: Risk factors for neurosurgical site infections after craniotomy: a critical reappraisal of antibiotic prophylaxis on 4,578 patients. Br J Neurosurg 19:155-162, 2005

10. Lassen B, Helseth E, Rønning P, Scheie D, Johannesen TB, Mæhlen J, et al: Surgical mortality at 30 days and complications leading to recraniotomy in 2630 consecutive craniotomies for intracranial tumors. Neurosurgery 68:1259-1269, 2011

11. Lepänluoma M, Takala R, Kotkansalo A, Rahi M, Ikonen TS: Surgical safety checklist is associated with improved operating room safety culture, reduced wound complications, and unplanned readmissions in a pilot study in neurosurgery. Scand J Surg 103: 66-72, 2014

12. Lietard C, Thébaud V, Besson G, Lejeune B: Risk factors for neurosurgical site infections: an 18-month prospective survey. J Neurosurg 109:729-734, 2008

13. McConnell DJ, Fargen KM, Mocco J: Surgical checklists: a detailed review of their emergence, development, and relevance to neurosurgical practice. Surg Neurol Int 3:2, 2012

14. Mollman HD, Haines SJ: Risk factors for postoperative neurosurgical wound infection. A case-control study. J Neurosurg 64:902-906, 1986

15. Parker SL, Shau DN, Mendenhall SK, McGirt MJ: Factors influencing 2-year health care costs in patients undergoing revision lumbar fusion procedures. J Neurosurg Spine 16:323-328, 2012

16. Quadery LA, Medlery AV, Miles J: Factors affecting the incidence of wound infection in Neurosurgery. Acta Neurochir (Wien) 39:133-141, 1977

17. Rolston JD, Han SJ, Lau CY, Berger MS, Parsa AT: Frequency and predictors of complications in neurological surgery: national trends from 2006 to 2011. J Neurosurg 120:736745,2014

18. Semel ME, Resch S, Haynes AB, Funk LM, Bader A, Berry WR, et al: Adopting a surgical safety checklist could save money and improve the quality of care in U.S. hospitals. Health Aff (Millwood) 29:1593-1599, 2010

19. Sewell M, Adebibe M, Jayakumar P, Jowett C, Kong K, Vemulapalli K, et al: Use of the WHO surgical safety checklist in trauma and orthopaedic patients. Int Orthop 35:897-901, 2011
20. Street JT, Lenehan BJ, DiPaola CP, Boyd MD, Kwon BK, Paquette SJ, et al: Morbidity and mortality of major adult spinal surgery. A prospective cohort analysis of 942 consecutive patients. Spine J 12:22-34, 2012

21. Takala RS, Pauniaho SL, Kotkansalo A, Helmiö P, Blomgren $\mathrm{K}$, Helminen M, et al: A pilot study of the implementation of WHO surgical checklist in Finland: improvements in activities and communication. Acta Anaesthesiol Scand 55:12061214, 2011

22. van Ek B, Dijkmans BA, van Dulken H, van Furth R: Antibiotic prophylaxis in craniotomy: a prospective double-blind placebo-controlled study. Scand J Infect Dis 20:633-639, 1988

23. van Klei WA, Hoff RG, van Aarnhem EE, Simmermacher RK, Regli LP, Kappen TH, et al: Effects of the introduction of the WHO "Surgical Safety Checklist" on in-hospital mortality: a cohort study. Ann Surg 255:44-49, 2012

24. Weiser TG, Haynes AB, Dziekan G, Berry WR, Lipsitz SR, Gawande AA: Effect of a 19-item surgical safety checklist during urgent operations in a global patient population. Ann Surg 251:976-980, 2010

25. Whitmore RG, Stephen J, Stein SC, Campbell PG, Yadla S, Harrop JS, et al: Patient comorbidities and complications after spinal surgery: a societal-based cost analysis. Spine (Phila Pa 1976) 37:1065-1071, 2012

26. Wong JM, Bader AM, Laws ER, Popp AJ, Gawande AA: Patterns in neurosurgical adverse events and proposed strategies for reduction. Neurosurg Focus 33(5):E1, 2012

27. Wong JM, Panchmatia JR, Ziewacz JE, Bader AM, Dunn IF, Laws ER, et al: Patterns in neurosurgical adverse events: intracranial neoplasm surgery. Neurosurg Focus 33(5):E16, 2012

28. Wong JM, Ziewacz JE, Ho AL, Panchmatia JR, Bader AM, Garton HJ, et al: Patterns in neurosurgical adverse events: cerebrospinal fluid shunt surgery. Neurosurg Focus 33(5):E13, 2012

29. Wong JM, Ziewacz JE, Ho AL, Panchmatia JR, Kim AH, Bader AM, et al: Patterns in neurosurgical adverse events: open cerebrovascular neurosurgery. Neurosurg Focus 33(5):E15, 2012

30. Wong JM, Ziewacz JE, Panchmatia JR, Bader AM, Pandey AS, Thompson BG, et al: Patterns in neurosurgical adverse events: endovascular neurosurgery. Neurosurg Focus 33(5):E14, 2012

\section{Author Contributions}

Conception and design: Ikonen, Lepänluoma, Rahi. Acquisition of data: Lepänluoma. Analysis and interpretation of data: all authors. Drafting the article: all authors. Critically revising the article: Ikonen, Lepänluoma, Rahi. Approved the final version of the manuscript on behalf of all authors: Ikonen. Statistical analysis: Löyttyniemi. Study supervision: Ikonen.

\section{Correspondence}

Tuija S. Ikonen, Administrative Centre, Hospital District of Southwest Finland, P.O. Box 52, Turku FI-20521, Finland. email: tuija.ikonen@tyks.fi. 